\title{
para-Selective nitration of halogenobenzenes using a nitrogen dioxide-oxygen-zeolite system
}

\author{
Keith Smith,* Saeed Almeer and Steven J. Black \\ Centre for Clean Chemistry, Department of Chemistry, University of Wales Swansea, Swansea, UK SA2 8PP. \\ E-mail: K.Smith@swansea.ac.uk
}

\section{Received (in Cambridge, UK) 10th May 2000, Accepted 5th July 2000 Published on the Web 2nd August 2000}

\begin{abstract}
The nitration of halogenobenzenes using zeolite $\mathrm{H} \beta$ or zeolite HY as a solid inorganic catalyst and a combination of liquid nitrogen dioxide and gaseous oxygen as the nitrating reagent leads to high yields and significant para-selectivities in a relatively clean process for aromatic nitration.
\end{abstract}

Electrophilic aromatic substitution reactions are of considerable importance in the production of fine chemicals. However, the traditional processes suffer a number of disadvantages, such as low selectivity towards the desired product and the requirement for large quantities of mineral or Lewis acids as activators. In turn these acids are responsible for corrosion problems within the plant and the generation of large volumes of spent reagents, which, given the current environmentally conscious climate, are increasingly unacceptable. Major efforts are therefore being made towards developing processes that can reduce the volumes of spent liquors produced. Inorganic solids can offer significant benefits for these processes by providing both effective catalysis and, in some cases, enhanced selectivity. Additionally they are easily removed from reaction mixtures and in some cases recycling is possible. For example, we have utilised zeolites to enhance the para-selectivity in chlorination, ${ }^{1}$ bromination, ${ }^{2}$ acylation ${ }^{3}$ and methanesulfonylation ${ }^{4}$ reactions of simple aromatic substrates.

Aromatic nitro compounds represent particularly versatile chemical feedstocks for a wide range of industrial products, such as pharmaceuticals, agrochemicals, dyestuffs and explosives. Traditionally, nitration has been performed by a mixture of nitric and sulfuric acids (mixed acid method). ${ }^{5}$ However, the method is notoriously unselective for nitration of substituted aromatic compounds and the disposal of the spent acid reagents presents a serious environmental issue. In order to address these problems several alternative methods for aromatic nitration have been developed recently. For example, lanthanide triflates have been used to catalyse nitration with nitric acid, which avoids the use of large volumes of sulfuric acid in the process. ${ }^{6}$ However, this provides no enhancement of selectivity. Selectivity of the nitration process can be enhanced by solid catalysts such as clays, but primarily zeolites, which can improve selectivity using alkyl nitrates, ${ }^{7}$ acyl nitrates, ${ }^{8}$ or even nitric acid itself. ${ }^{9,10}$ We have reported the use of zeolite $\mathrm{H} \beta$ in conjunction with a mixture of acetic anhydride and nitric acid, which currently offers the best combination of yield and paraselectivity for nitration of simple aromatic compounds. ${ }^{11}$ None of these methods, however, are totally devoid of disadvantages.

Another approach towards clean nitration involves the use of dinitrogen tetroxide in combination with oxygen or ozone as an oxidant. ${ }^{12}$ The method where ozone is employed most likely involves dinitrogen pentoxide, as this is known to be a highly active nitrating agent. The method utilising oxygen is less clear cut and requires the use of tris(pentane-2,4-dionato)iron(III) $\left(\mathrm{Fe}(\mathrm{acac})_{3}\right)$ as a catalyst in an organic solvent. ${ }^{13}$ In principle, this could lead to a highly atom-efficient process [eqn. (1)], but it is not regioselective. Therefore, we decided to study the use of dinitrogen tetroxide as a nitrating agent in the presence of zeolites, in order to determine if they were able to catalyse the process and impart para-selectivity.

$$
4 \mathrm{ArH}+2 \mathrm{~N}_{2} \mathrm{O}_{4}+\mathrm{O}_{2} \stackrel{\text { Catalyst }}{\longrightarrow} 4 \mathrm{ArNO}_{2}+2 \mathrm{H}_{2} \mathrm{O}
$$

Zeolites have been used before in the vapour phase nitration of aromatic compounds using nitrogen dioxide. However, this process did not involve oxygen, was complicated, required a high flow rate for the carrier gas $\left(\mathrm{N}_{2}, 880 \mathrm{ml} \mathrm{min}^{-1}\right)$ and showed poor para-selectivity. ${ }^{14}$ We now report that certain zeolites can indeed catalyse the process of nitration, as shown in eqn. (1), whilst simultaneously providing enhanced paraselectivity.

Initially, an attempt was made to reproduce approximately the conditions of Suzuki for nitration of chlorobenzene. Liquid $\mathrm{N}_{2} \mathrm{O}_{4}$ (approx. $10 \mathrm{ml}$ ) was condensed into a trap at $-78^{\circ} \mathrm{C}$ and was then warmed to $0{ }^{\circ} \mathrm{C}$. $\mathrm{Fe}(\mathrm{acac})_{3}(0.355 \mathrm{~g})$ and chlorobenzene $(10 \mathrm{mmol})$ were then added, the system was flushed with oxygen and the mixture was stirred at $0{ }^{\circ} \mathrm{C}$ for $48 \mathrm{~h}$. The product thus obtained contained nitrochlorobenzenes in proportions $(2-: 3-: 4$-nitrochlorobenzene proportions of $32:<1: 67)$ that approximated to those reported by Suzuki, but also showed significant quantities of a product based upon nitration of acetylacetone.

We then carried out similar reactions in which various zeolites were used as catalysts instead of $\mathrm{Fe}(\mathrm{acac})_{3}$ in an attempt to determine which zeolite, if any, would be the most applicable to para-selective aromatic nitration. Zeolite $\beta$ and zeolite $Y$ have three dimensional channels and large pore sizes and were selected on this basis. Mordenite, which has linear large pores, and ZSM-5, which has a medium pore size, were chosen for comparison. Additionally, variation of the cation type was undertaken, with $\mathrm{H}^{+}, \mathrm{Na}^{+}, \mathrm{K}^{+}$and $\mathrm{NH}_{4}^{+}$being used in the case of zeolite $\beta$, and $\mathrm{H}^{+}$and $\mathrm{Na}^{+}$in the case of zeolite $\mathrm{Y}$. Finally, zeolite ZSM-5 was tested with two specific Si/Al ratios. Thus, the effects of pore size, channel structure, acidity, cation size and $\mathrm{Si} / \mathrm{Al}$ ratio could all be assessed. A reaction in the presence of chromatographic silica was also included for comparison. The results are shown in Table 1.

As shown in Table 1, reaction occurred in the presence of all of the zeolites, and all of the reactions gave higher yields than in the absence of any catalyst. The large, three-dimensionalpore zeolites gave higher yields, comparable with those achieved with $\mathrm{Fe}(\mathrm{acac})_{3}$ as catalyst, but the medium pore zeolites and the linear large pore zeolite gave lower yields, as did the silica. All of the zeolites demonstrated higher paraselectivity than that obtained with $\mathrm{Fe}(\mathrm{acac})_{3}$, except for $\mathrm{NH}_{4} \beta$. This last result may reflect the fact that this was the only zeolite not calcined (heated in air to a high temperature), since this would have caused loss of ammonia and formation of $\mathrm{H} \beta$.

Mordenite and ZSM-5 gave lower para-selectivities as well as lower yields, which probably reflects more restricted diffusion through the pores and competition from reaction at the external surface of the solid. The selectivity was also low for the reaction in the presence of silica. The ZSM-5 sample with the higher $\mathrm{Si} / \mathrm{Al}$ ratio gave a higher para-selectivity than that with the lower ratio, possibly because of the process of dealumination, which would have opened up the pore structure of 
Table 1 The effect of zeolite type on the nitration of chlorobenzene ${ }^{a}$

\begin{tabular}{|c|c|c|c|c|c|c|c|}
\hline \multirow[b]{2}{*}{ Zeolite } & \multirow[b]{2}{*}{$\mathrm{Si} / \mathrm{Al}$} & \multirow[b]{2}{*}{$t / \mathrm{h}$} & \multirow{2}{*}{$\begin{array}{l}\text { Conversion } \\
(\%)^{b}\end{array}$} & \multirow{2}{*}{$\begin{array}{l}\text { Yield } \\
(\%)^{b}\end{array}$} & \multicolumn{3}{|c|}{ Proportions ${ }^{b}$} \\
\hline & & & & & ortho & meta & para \\
\hline None ${ }^{c}$ & - & 50 & 6 & 2 & 39 & 0 & 61 \\
\hline $\mathrm{SiO}_{2}{ }^{c}$ & - & 50 & 40 & 28 & 29 & $<1$ & 70 \\
\hline $\mathrm{H} \beta$ & 25 & 50 & 100 & 90 & 14 & $<1$ & 85 \\
\hline $\mathrm{Na} \beta$ & 24 & 50 & 100 & 96 & 15 & 0 & 85 \\
\hline $\mathrm{K} \beta$ & 24 & 50 & 97 & 92 & 21 & 0 & 79 \\
\hline $\mathrm{NH}_{4} \beta$ & 25 & 50 & 76 & 70 & 30 & 1 & 69 \\
\hline $\mathrm{HY}$ & 30 & 50 & 100 & 91 & 16 & 2 & 82 \\
\hline $\mathrm{NaY}$ & 28 & 50 & 100 & 91 & 16 & 1 & 83 \\
\hline HMord. & 10.5 & 50 & 36 & 28 & 27 & 0 & 73 \\
\hline HZSM-5 & 50 & 72 & 44 & 42 & 28 & 2 & 70 \\
\hline HZSM-5 & 150 & 72 & 48 & 32 & 20 & $<1$ & 79 \\
\hline
\end{tabular}

${ }^{a}$ All reactions were carried out with zeolite $(1.0 \mathrm{~g})$, chlorobenzene $(10.0$ $\mathrm{mmol}), 1,2$-dichloroethane $(30 \mathrm{ml})$ and nitrogen dioxide $(\mathrm{ca} .10 \mathrm{ml})$ at $0{ }^{\circ} \mathrm{C}$. ${ }^{b}$ Calculated by quantitative GC. ${ }^{c}$ For comparison.

the zeolite, causing it somewhat to resemble the larger pore systems. However, the yield with the higher $\mathrm{Si} / \mathrm{Al}$ ratio sample was less, possibly because of the lower density of effective catalytic sites. Interestingly, the nature of the cation present appeared to have a negligible effect on the reactions, the $\mathrm{H}^{+}$, $\mathrm{Na}^{+}$and $\mathrm{K}^{+}$forms of the zeolites giving very similar results for each reaction where comparison was possible. Evidently, the process does not rely upon strong acid catalysis and does not depend significantly on cation size. Perhaps the role of the active site is merely to bring together the reagents and substrates within the confines of the pores by simple co-adsorption. Alternatively, perhaps the active site facilitates cleavage of dinitrogen tetroxide to give monomeric nitrogen dioxide, which has been suggested as the active reagent in vapour phase reactions. ${ }^{15}$

Zeolites $\mathrm{H} \beta$ and $\mathrm{Na} \beta$ produced the greatest selectivity for para-chloronitrobenzene $(85 \%)$ and the highest yields (90 and $96 \%$ ). Therefore, zeolite $\mathrm{H} \beta$ was tested with a range of other substrates. The results are shown in Table 2 .

Table 2 The nitration of toluene, benzene and halogenobenzenes with nitrogen dioxide and zeolite $\mathrm{H} \beta$ in 1,2-dichloroethane ${ }^{a}$

\begin{tabular}{lcclllll}
\hline & & & & \multicolumn{2}{l}{ Proportions $^{b}$} \\
\cline { 5 - 8 } Substrate & $t / \mathrm{h}$ & $\begin{array}{l}\text { Conversion } \\
(\%)^{b}\end{array}$ & $\begin{array}{l}\text { Yield } \\
(\%)^{b}\end{array}$ & ortho & meta & para \\
\hline Toluene & 24 & 100 & 85 & 53 & 2 & 45 \\
Benzene & 45 & 55 & 50 & - & - & - \\
Fluorobenzene & 48 & 100 & 95 & 7 & 0 & 93 \\
Chlorobenzene & 48 & 98 & 95 & 14 & $<1$ & 85 \\
Bromobenzene & 48 & $>99$ & 94 & 22 & $<1$ & 77 \\
Iodobenzene & 48 & 99 & 95 & 37 & 1 & 62
\end{tabular}

a All reactions were carried out with zeolite $(1.0 \mathrm{~g})$, substrate $(10.0 \mathrm{mmol})$, 1,2-dichloroethane $(30 \mathrm{ml})$ and nitrogen dioxide $(\mathrm{ca} .10 \mathrm{ml})$ at $0{ }^{\circ} \mathrm{C}$. ${ }^{b}$ Calculated by quantitative GC.
After $24 \mathrm{~h}$ toluene had been completely consumed and produced a reasonable yield of mononitrotoluenes $(85 \%)$. The para-selectivity was fairly low, though greater than for mixed acid nitrations. The reaction with benzene was slow, being only ca. $50 \%$ complete after $48 \mathrm{~h}$. However, all the halogenobenzenes gave good yields and reasonable para-selectivities. This work therefore demonstrates that zeolites $\beta$ and $\mathrm{Y}$, with $\mathrm{H}^{+}, \mathrm{Na}^{+}$or $\mathrm{K}^{+}$cations, can be efficient inorganic catalysts for the nitration of halogenobenzenes with dinitrogen tetroxide and oxygen and produce high para-selectivities and yields compared to classical nitration methods.

Furthermore, this method represents a low energy and potentially clean synthesis of halonitrobenzenes using an easily recycled solvent and catalyst system. However, at this preliminary point the reactions involve a large excess of dinitrogen tetroxide, long reaction times and the use of an undesirable chlorinated solvent. Therefore, our future efforts in this area will be concentrated on minimising these factors.

The reaction of chlorobenzene illustrates the general procedure for the nitration process. In an ice-water cooling bath was placed a $100 \mathrm{ml}$ round-bottom flask containing a mixture of chlorobenzene $(10 \mathrm{mmol})$, zeolite $(1.0 \mathrm{~g})$, and 1,2-dichloroethane $(30 \mathrm{ml})$. The flask was flushed with oxygen gas for 20 min at $0^{\circ} \mathrm{C}$. Liquid nitrogen dioxide ( $c a .10 \mathrm{ml}, c a .280 \mathrm{mmol}$ ) was added quickly all at once to the stirred mixture, and the flask was connected to an oxygen gas balloon. After $50 \mathrm{~h}$ at $0{ }^{\circ} \mathrm{C}$, the mixture was filtered through a medium porosity sintered glass funnel, and the filtrate was diluted with water. 1,2-Dichloroethane was added and the organic phase was separated and dried over magnesium sulfate. The isomer distribution was determined by gas chromatography (PU 4400) (octadecane was added as an internal standard).

\section{Notes and references}

1 K. Smith, M. Butters, W. E. Paget, D. Goubet, E. Fromentin and B. Nay, Green Chem., 1999, 2, 83.

2 K. Smith, P. He and A. Taylor, Green Chem., 1999, 1, 35.

3 K. Smith, Z. Zhenhua and P. K. G. Hodgson, J. Mol. Catal. A, 1998, 134, 121.

4 K. Smith, G. M. Ewart and K. R. Randles, J. Chem. Soc., Perkin Trans. 1, 1997, 1085 .

5 E. R. Ward, Chem. Br., 1979, 15, 297.

6 F. J. Waller, A. G. M. Barrett, D. C. Braddock and D. Ramprasad, Chem. Commun., 1997, 613.

7 T. J. Kwok and K. Jayasuriya, J. Org. Chem., 1994, 59, 4939.

8 A. Cornelis, A. Gerstmans and P. Laszlo, Chem. Lett., 1988, 1839.

9 K. Jayasuriya and R. Damavarapu, US Pat. Appl., 5946638, 1999.

10 B. M. Choudary, M. Sateesh, M. L. Kantam, K. K. Rao, K. V. R. Prasad, K. V. Raghavan and J. A. R. P. Sarma, Chem. Commun., 2000, 25.

11 K. Smith, A. Musson and G. A. DeBoos, J. Org. Chem., 1998, 63, 8448.

12 H. Suzuki and T. Mori, J. Chem. Soc., Perkin Trans. 2, 1994, 479.

13 H. Suzuki, S. Yonezawa, N. Nonoyama and T. Mori, J. Chem.Soc., Perkin Trans. 1, 1996, 2385.

14 I. Schumacher, Eur. Pat. Appl., 0053031, 1981

15 A. Germain, T. Akouz and F. Figueras, J. Catal., 1994, 147, 163; A. Germain, T. Akouz and F. Figueras, Appl. Catal. A: Gen., 1996, 136, 37. 